\title{
Whole Body Scan
}

National Cancer Institute

\section{Source}

National Cancer Institute. Whole Body Scan. NCI Thesaurus. Code C95004.

A series of scans of a subject taken at sequential bed positions as the bed moves through the scanner. The images, each limited by an axial field of view, can then be pieced together to give an extended length image of the subject. A whole body scan contrasts with a single bed position scan in which only a rather limited region within the subject is to be studied. 